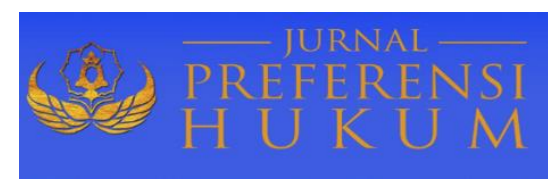

Jurnal Preferensi Hukum | ISSN: 2746-5039

Vol. 2, No. 1 - Februari 2021, Hal. 22-26| Available online at https://www.ejournal.warmadewa.ac.id/index.php/juprehum

DOI: https://doi.org/10.22225/jph.2.1.3045.22-26

\title{
PERAN TP4D KEJAKSAAN NEGERI DENPASAR DALAM MENGAWAL PEMBANGUNAN DAERAH DALAM PENCEGAHAN TINDAK PIDANA KORUPSI
}

\author{
Ni Ketut Puput Cahyaningsih, I Gusti Bagus Suryawan, I Nengah Laba \\ Fakultas Hukum Universitas Warmadewa, Denpasar-Bali, Indonesia \\ cahyaningsihpuput@gmail.com
}

\begin{abstract}
Abstrak
Penerapan kebijakan strategis pemberantasan korupsi melalui penindakan saja tidak akan berhasil tanpa dibarengi upaya pencegahan sebagai bentuk penyadaran bagi masyarakat akan bahaya korupsi yang pada akhirnya membangkitkan semangat antikorupsi diseluruh lapisan masyarakat. Intruksi Jaksa Agung Nomer: INS-001/JA/10/2015 tentang pembentukan dan pelaksanaan tugas Tim Pengawal Pengamanan Pemerintahan Dan Pembangunan Pusat maupun Daerah (TP4D). Pembentukan Tim ini dimaksudkan untuk pengamanan dan pengawalan pemerintah dalam pelaksanaan pembangunan proyek strategis agar berhasil maksimal dan untuk mencegah terjadinya tindak pidana korupsi. Penelitian ini bertujuan untuk mengetahui peran Tim Pengawal Pengamanan Pemerintahan dan Pembangunan Daerah (TP4D) Kejaksaan Negeri Denpasar dalam upaya mencegah tindak pidana korupsi dan untuk mengetahui hambatan yang dialami oleh Tim Pengawal Pengamanan Pemerintahan dan Pembangunan Daerah (TP4D) Kejaksaan Negeri Denpasar dalam mengawal pembangunan daerah. Metode penelitian yang digunakan yaitu metode penelitian yuridis empiris dan menggunakan teknik purposive. Hasil analisis menunjukan bahwa berdasarkan wawancara kepada Kepala Seksi Bidang Intelijen Kejaksaan Negeri Denpasar, Kasubsi Ekonomi Keuangan dan Pembangunan Strategis beserta Kasubsi Penyidikan dapat disimpulkan: (1) Peran TP4D Kejaksaan Negeri Denpasar dalam mencegah tindak pidana korupsi diantaranya memberikan masukan-masukan, saran, pendapat (legal opinion) terhadap jalannya proyek pembangunan pemerintah daerah agar tidak terjadinya penyalahgunaan wewenang (2) Hambatan yang dialami TP4D Kejaksaan Negeri Denpasar dalam mengawal pembangunan di Kota Denpasar terdapat dua hambatan diantaranya hambatan teknis dan hambatan yuridis.
\end{abstract}

Kata Kunci: Tim TP4D, Pencegahan, Korupsi

\begin{abstract}
The implementation of strategic policies to eradicate corruption through prosecution alone will not succeed without being accompanied by preventive efforts as a form of awareness for the public about the dangers of corruption which ultimately arouses the spirit of anti-corruption throughout society. Instruction of the Attorney General Number: INS-001 / JA / 10/2015 regarding the formation and implementation of the duties of the Central and Regional Government Security Guard and Development Team (TP4D). The formation of this team is intended to safeguard and guard the government in the implementation of strategic project development so that it will be maximally successful and to prevent the occurrence of criminal acts of corruption. This study aims to determine the role of the Regional Government and Regional Development Security Guard Team (TP4D) in the effort to prevent criminal acts of corruption and to find out the obstacles experienced by the Regional Government and Regional Development Security Guard Team (TP4D) in guarding regional development. The research method used is juridical empirical research method and using purposive technique. The results of the analysis show that based on interviews with the Head of the Intelligence Section of the Denpasar District Prosecutor's Office, the Head of the Financial Economics and Strategic Development Sub-Department and the Investigation Sub-Section Head, it can be concluded that: (1) The role of TP4D Denpasar District Prosecutor's Office in preventing criminal acts of corruption includes providing inputs, suggestions, opinions ( legal opinion) on the course of local government development projects so that there is no abuse of authority (2) Obstacles experienced by the Denpasar District Prosecutor's TP4D in guarding development in Denpasar City are two obstacles including technical obstacles and juridical obstacles.
\end{abstract}

Keywords: TP4D Team, Prevention, Corruption 


\section{PENDAHULUAN}

Di semua Negara di dunia mengalami permasalahn atau kasus korupsi tidak terkecuali Indonesia. Dalam rangka melaksanakan Keputusan Jaksa Agung Republik Indonesia Nomor 152 tahun 2015 tentang Pembentukan TP4P dan TP4D maka Kejaksaan Republik Indonesia mengeluarkan Intruksi Jaksa Agung Republik Indonesia Nomor 001 tahun 2015 Pembentukan dan Pelaksanaan Tugas TP4P dan TP4D disebabkan karena pada tahun 2015 lalu penyerapan anggaran yang dialami oleh pemerintah pusat maupun daerah sangat rendah dikarenakan banyak pejabat daerah yang takut dipidanakan apabila salah atau menyimpang dalam menggunakan anggarannya. Tindakan para pejabat dalam mengelola keungan perlu di awasi karena tanpa pengawasan pejabat dapat melakuan korupsi. Korupsi adalah sebuah tindakan penggelapan uang yang bukan miliknya (Siahaan, 2013).

Dengan dibentuknya TP4D diharapkani setiap pejabat daerah dari Satuan Kerja Perangkat Daerah (SKPD) bisa meminta pendampingan untuk penggunaan anggaran keuangan daerah sehingga semuanya bisa tepat sasaran dan program pembangunan dapat berjalan dengan baik. Dimana pendampingan yang diberikan oleh TP4D kepada SKPD ini sampai pada pengawasan hasil pembangunan yang dilakukan.

Berkaitan dengan upaya untuk pencegahan korupsi, berikut ini beberapa penelitian terdahulu telah mengkaji tentang bagaimana korupsi bisa dicegah sekaligus fakta-fakta tentang kasus korupsi, seperti penelitian yang dilakukan oleh Bandeira (2013); Lewis \& Hendrawan (2019); Locatelli, Mariani, Sainati, \& Greco (2017); Márquez (2015); Peerthum, Gunputh, \& Luckho (2020); Widojoko (2017). Berdasarkan uraian di atas, penelitian ini bertujuan untuk mengetahui peran TP4D Kejaksaan Negeri Denpasar dalam upaya pencegahan Tindak Pidana Korupsi dan untuk mengetahui hambatan yang dihadapi oleh TP4D Kejaksaan Negeri Denpasar dalam mengawal pembangunan daerah di Kota Denpasar.

\section{METODE PENELITIAN}

Penelitian ini menggunakan metode Yuridis Empiris. Sumber bahan hukum yang digunakan ada dua bentuk yaitu sumber data primer dan sumber data sekunder. Data Primer meliputi data dan wawancara yang berkaitan dengan Tim Pengawal Pengamanan Pemerintahan dan Pembangunan Daerah Kejaksaan Negeri Denpasar sedangkan untuk sumber data sekunder meliputi UUDNRI 1945, UU No 16 tahun 2004 tentang Kejaksaan RI, Keputusan Jaksa Agung Nomor: KEP-152/A/JA/10/2015 dan Intruksi Jaksa Agung Nomor: INS-001/A/JA/10/2015. Lokasi Penelitian ini dilakukan di Kejaksaan Negeri Denpasar Tipe A untuk rayon Denpasar yang beralamat di Jalan PBn. Sudirman No. 3 Denpasar - Bali. Teknik pengumpulan data yang diterapkan yaitu teknik studi kepustakaan melalui data data dokumen dan teknik lapangan yang dilakukan dengan wawancara (Suratman \& Philips Dillah, 2012). Kemudian, teknik pengolahan dan analisis data yang disajikam secara deskriptif kualitatitif yaitu dilakukan dengan menggambarkan data yang dihasilkan dalam bentuk uraian kalimat atau penjelasan.

\section{HASIL DAN PEMBAHASAN}

\section{Peran TP4D Kejaksaan Negeri Denpasar dalam Pencegahan Tindak Pidana Korupsi}

Berdasarkan hasil wawancara dengan Kepala Seksi Intelijen Kejaksaan Negeri Denpasar, I Made Agus Sastrawan, SH., di Kejaksaan Negeri Denpasar tanggal 4 November 2018. Sebelum membahas peran Tim TP4D ini, secara filosofi TP4D dibentuk merupakan program Nawacita dari Presiden Joko Widodo yang didasari dengan Intruksi Presiden Nomor 7 tahun 2015 tentang Aksi Pencegahan dan Pemberantasan Korupsi. Sehingga dibentuklah TP4D berdasarkan Keputusan Jaksa Agung Republik Indonesia Nomor: KEP-152/A/JA/10/2015 tentang Pembentukan Tim Pengawal, Pengaman Pemerintahan dan Pembangunan (TP4), maka Kejaksaan Republik Indonesia juga mengeluarkan Instruksi Jaksa Agung Republik Indonesia Nomor: INS-001/A/JA/10/2015 tentang Pembentukan dan Pelaksanaan Tugas Tim Pengawal, Pengaman Pemerintahan dan Pembangunan Pusat, yang selanjutnya disingkat menjadi (TP4P) dan Daerah (TP4D). Dalam hal ini TP4D Kejaksaan Negeri Denpasar memiliki peran memberikan masukan-masukan, saran, pendapat hukum (Legal Opinion) terhadap jalannya proyek pembangunan pemerintah daerah untuk mencegah adanya keragu-raguan, penyalahgunaan wewenang dari pemerintah dalam menyalurkan anggarannya terhadap berlangsungnya proyek pembangunan strategis di lapangan. Selain itu TP4D Kejaksaan Negeri Denpasar juga berperan melakukan pengawalan dan pengamanan dalam setiap tahapan program 
pembangunan dari awal sampai akhir untuk mencegah terjadinya permasalahan hukum sehingga pembangunan pemerintah daerah dapat berjalan tepat mutu, tepat sasaran, tepat waktu dan dapat berjalan sesuai dengan apa yang diharapkan.

Adapun bentuk-bentuk pengawalan yang dikawal oleh Tim Pengawal Pengamanan Pemerintahan dan Pembangunan Daerah (TP4D) Kejaksaan Negeri Denpasar adalah pembangunan yang menggunakan APBD, APBN yang menggunakan keuangan negara baik itu BUMN, BUMD, maupun organisasi pemerintah lainnya melalui pengawalan dan pengamanan antara lain: Pada Dinas Pendidikan, Pemuda dan Olahraga Kota Denpasar sebanyak 5 proyek (Proyek Pembangunan Gedung Lantai III SDN 5 Dangin Puri, Proyek Pembangunan Gedung Lantai III SDN 4 Sesetan, Proyek Pembangunan Gedung Lantai III SDN 7 Sesetan, Proyek Pembangunan Gedung Lantai III SDN 2 Pedungan, Proyek Pembangunan Gedung Lantai III DisDikpora Kota Denpasar), Pada Dinas Pekerjaan Umum dan Perumahan Rakyat Kota Denpasar sebanyak 9 proyek (Proyek Pembangunan Pasar Badung Kota Denpasar, Proyek Pembangunan Gedung Balai Budaya Kota Denpasar, Proyek Peningkatan Jalan Buana Raya di Kecamatan Denpasar Barat, Proyek Peningkatan Jalan dan Pembuatan Trotoar Jalan Suwung Batan Kendal dan Jalan Pemelis di Kecamatan Denpasar Selatan, Proyek Penigkatan Struktur Jalan dan Pembuatan Trotoar ruas Jalan Pulau Kawe di Kecamatan Denpasar Barat, Proyek Peningkatan Kapasitas Jalan dan Pembuatan Trotoar Jalan Pulau Singkep di Kecamatan Denpasar Selatan, Proyek Peningkatan Jalan dan Pembuatan Trotoar Jalan Noja di Kecamatan Denpasar Timur, Proyek Penataan Tukad Badung Lanjutan, Proyek Pembangunan DSDP Tahap II di Pemogan dan Sekitarnya), Pada Dinas Perindustrian dan Perdagangan Kota Denpasar sebanyak 1 proyek (Proyek Pembangunan/Revitalisasi fisik Pasar Kerta Waringin Sari, Desa Pakraman Anggabaya, Kelurahan Penatih, Kecamatan Denpasar Timur), Pada Sekretariat Dewan Perwakilan Rakyat Kota Denpasar sebanyak 1 proyek (Proyek Pengadaan Meubelair dan Pakaian Dinas DPRD Kota Denpasar).

\section{Hambatan yang Dialami Tim TP4D dalam Mengawal Pembangunan Daerah Di Kota Denpasar}

Berdasarkan hasil wawancara dengan I Kadek Wahyudi Ardika, SH selaku Kepala Sub Seksi Penyidikan Tindak Pidana Khusus di Kejaksaan Negeri Denpasar pada tanggal 10 Desember 2018 mengenai hambatan-hambatan yang dihadapi oleh Tim Pengawal Pengamanan Pemerintahan dan Pembangunan Daerah atau yang disingkat menjadi (TP4D) Kejaksaan Negeri Denpasar secara teknis di lapangan merupakan suatu halangan atau rintangan melaksanakan tugas wewenang dalam pendampingan dan pengawalan proses pembangunan, hambatan-hambatannya terdiri dari hambatan yuridis dan hambatan teknis (hambatan dilapangan). Adapun hambatan-hambatan teknis yang dihadapi dihadapi oleh Tim TP4D Kejaksaan Negeri Denpasar meliputi:

1 Keterbatasan personil sehingga ada beberapa proyek yang tidak berlanjut di monitoring Jumlah Jaksa di Kejaksaan Negeri Denpasar terdiri dari kurang lebih 30 orang yang tersebar di beberapa bidang, di bidang Intelijen jumlah Jaksa yang ada 6 orang beserta Kepala Seksi Intelijen. Sehingga dari jumlah proyek yang dimohonkan pemerintah Kota Denpasar tidak sebanding kadang kala 1 orang bisa mendampingi 5 proyek pembangunan hal tersebut Tim TP4D Kejaksaan Negeri Denpasar dalam melakukan monitoring dan evaluasi bersamaan tidak maksimal. Untuk mengurangi hal tersebut Tim TP4D Kejaksaan Negeri Denpasar memprioritaskan mana proyek yang dianggap proyek strategis yang memiliki nilai besar dan rentan terjadinya tindak pidana korupsi maka itu yang difokuskan diberikan pendampingan oleh TP4D Kejaksaan Negeri Denpasar.

2 Keterbatasan biaya

Keterbatasan biaya yang menjadi hambatan yang dialami oleh TP4D Kejaksaan Negeri Denpasar disebakan karena pembiayaan terhadap Tim TP4D melali DIPA jumlahnya kecil, sehingga dalam melakukan monitoring dan evalusi di lapangan Tim TP4D tidak diperkenankan untuk menerima sesuatu apapun dari pihak pemerintah daerah, kontraktor proyek dan dari pejabat proyek lainnya.

3 Terpecahnya fokus personil dengan tugas dan tanggung jawab lain (Multi Tugas)

Terpecahnya fokus personil dengan tugas dan tanggung jawab lain (Multi Tugas) disebabkan karena keanggotaan Tim TP4D Kejaksaan Negeri Denpasar terdiri dari Jaksa Bidang Intelijen, Bidang Perdata dan Tata Usaha Negara (Datun), dan Bidang Tindak Pidana Khusus 
dimana tugas Jaksa bukan hanya harus terfokus pada tugas menjalankan pengawalan proyek saja akan tetapi jaksa memiliki tugas untuk memberikan penegakan hukum lainnya dan menjalankan persidangan ini dapat menyebabkan terpecahnya focus personil tugas dan tanggung jawab dalam melakukan pengawalan pengamanan pemerintahan dan pembangunan daerah.

4 Kekhawatiran jika hasil pelaksanaan tugas tidak sinkron dengan hasil audit BPK dan Aparatur Pengawasan Internal Pemerintah (APIP)

Pada awalnya, kekhawatiran Jaksa Tim TP4D sudah memberikan monitoring dan evaluasi saran, pendapat hukum (legal opinion) A, ternyata dilapangan tidak dilakukan A akan tetapi berita acara yang disarankan dengan dokumentasi tidak dilaksananakan. Otomatis menjadi berbeda dengan hasil audit BPK dan Aparatur Pengawas Internal Pemerintah (APIP) menjadi kekhawatiran Tim TP4D sehingga nanti dipandang tidak wajar. Untuk mencegah terjadinya hal seperti ini dari pihak pemohon terutama dari pemerintah daerah maupun dari pihak kontraktor, pengawas maupun panitia pelaksana proyek pembangunan harus berifat jujur dan terbuka untuk mencegah timbulnya tindak pidana korupsi.

5 Memverivikasi laporan pelaksanaan proyek pembangunan

Dalam melaksanakan pengawalan dan pengamanan proyek dengan komplesitasnya tahun berjalannya rata-rata 180 hari maupun multiyears sampai 2, 3 tahunan. Dengan adanya hal tersebut Tim TP4D Kejaksaan Negeri Denpasar harus memverivikasi langsung ke proyek tersebut seperti melakukan kunjungan langsung ke proyek tersebut menanyakan secara langsung.

6 Keberatan dari instansi lain karena mereka merasa diawasi terlalu ketat.

Dari sisi pemohon dalam hal ini pemerintah daerah merasa terlalu diawasi. Hambatan ini merupakan point terakhir sebenarnya dari sisi pemohon dalam mengajukan permohonan pengawalan dan pengamanan setiap instansi harus selalu siap karena itu merupakan permohonan dari instansi agar proyek dapat berjalan tepat pada sasarannya. Sedangkan untuk hambatan yuridis pada Tim Pengawal Pengamanan Pemerintahan dan Pembangunan Daerah (TP4D) khususnya pada tim TP4D Kejaksaan Negeri Denpasar yaitu (1) Dalam pelaksanaannya ada beberapa anggota tidak terlalu mengerti tentang Tupoksi TP4D. (2) Dalam penegakan hukum Tim Pengawal Pengamanan Pemerintahan dan Pembangunan Daerah (TP4D) tidak ada aturan khusus.

\section{SIMPULAN DAN SARAN}

\section{Simpulan}

Berdasarkan Instruksi Jaksa Agung Republik Indonesia Nomor: INS-001/A/JA/10/2015 Peran Tim TP4D Kejaksaan Negeri Denpasar memiliki peran yang sangat penting dalam mengawal pembangunan proyek strategis nasional untuk mencegah terjadinya tindak pidana korupsi. Dalam hal ini TP4D Kejaksaan Negeri Denpasar memiliki peran memberikan masukan-masukan, saran, pendapat (legal opinion) terhadap jalannya proyek pembangunan pemerintah daerah untuk mencegah adanya keragu-raguan dari pemerintah dalam menyalurkan anggarannya terhadap proyek pembangunan strategis di lapangan untuk mencegah terjadinya permasalahan hukum sehingga pembangunan pemerintah daerah dapat berjalan sesuai dengan apa yang diharapkan tepat mutu, tepat sasaran, tepat waktu sehingga tidak menghambat laju pembangunan daerah khususnya pembangunan di Kota Denpasar. Kemudian, hambatan Tim Pengawal Pengamanan Pemerintahan dan Pembangunan Daerah (TP4D) pada Kejaksaan Negeri Denpasar dapat dibagi menjadi dua hambatan yang dihadapi diantaranya hambatan teknis dan hambatan yuridis. Hambatan teknis meliputi hambatan yang dialami pada saat pelaksanaannya dilapangan dan adapun hambatan yuridis yang dialami oleh TP4D Kejaksaan Negeri Denpasar meliputi: (1) eterbatasan personil sehingga ada beberapa proyek yang tidak berlanjut di monitoring, (2) Keterbatasan biaya, (3) Terpecahnya fokus personil dengan tugas dan tanggung jawab lain (Multi Tugas), (4) Kekhawatiran jika hasil pelaksanaan tugas tidak sinkron dengan hasil audit BPK dan Aparatur Pengawasan Internal Pemerintah (APIP), (5) Memverivikasi laporan pelaksanaan proyek pembangunan, (6) Keberatan dari instansi lain karena mereka merasa diawasi terlalu ketat. 


\section{Saran}

Hendaknya instansi yang terkait dalam pembangunan, kontraktor maupun pejabat proyek selalu mematuhi aturan yang disarankan oleh Tim TP4D Kejaksaan Negeri Denpasar dan lebih bersifat terbuka, jujur dalam memberikan informasi mengenai proyek pembangunan yang ada di Kota Denpasar guna untuk mencegah terjadinya tindak pidana korupsi.

\section{DAFTAR PUSTAKA}

Bandeira, G. N. C. S. de M. (2013). "Corruption" and Social and Economic Criminal Law: Criminology, Criminal Policy, Political Science and Law \& Economics-A New Idea about Criminal Liability of Legal Entities. Tékhne, 11(2), 105-113.

Lewis, B. D., \& Hendrawan, A. (2019). The Impact of Majority Coalitions on Local Government Spending, Service Delivery, and Corruption in Indonesia. European Journal of Political Economy, 58(November), 178-191.

Locatelli, G., Mariani, G., Sainati, T., \& Greco, M. (2017). Corruption in Public Projects and Megaprojects: There is an Elephant in the Room! International Journal of Project Management, 35(3), 252-268.

Márquez, D. (2015). Mexican Administrative Law Against Corruption: Scope and Future. Mexican Law Review, $8(1), 75-100$.

Peerthum, S., Gunputh, R. P., \& Luckho, T. (2020). Assessing the Effectiveness of the Fight against PublicSector Corruption in Mauritius: Perception vs Reality. International Journal of Law, Crime and Justice, $63(\mathrm{xxxx}), 1-15$

Siahaan, M. (2013). Korupsi Penyakit Sosial yang Mematikan. Jakarta: Gramedia Pustaka Utama.

Suratman, \& Philips Dillah, H. (2012). Metode Penelitian Hukum. Bandung: Alfabeta.

Widojoko, J. D. (2017). Indonesia's Anticorruption Campaign: Civil Society versus the Political Cartel. The Changing Face of Corruption in the Asia Pacific: Current Perspectives and Future Challenges. Elsevier Ltd.

Undang-Undang Nomor 16 Tahun 2004 tentang Kejaksaan Republik Indonesia

Intruksi Presiden Nomor 7 tahun 2015 tentang Aksi Pencegahan dan Pemberantasan Korupsi

Keputusan Jaksa Agung RI Nomor : KEP-152/A/JA/10/2015 Tanggal 01 Oktober 2015 tentang Pembentukan Tim Pengawal dan Pengamanan Pemerintahan dan Pembangunan Pusat dan Daerah Kejaksaan Republik Indonesia

Intruksi Jaksa Agung RI Nomor : INS-001/A/JA/10/2015 Tanggal 05 Oktober 2015 tentang Pembentukan dan Pelaksanaan Tugas Tim Pengawal Pengamanan Pemerintahan dan Pembangunan Pusat dan Daerah Kejaksaan Republik Indonesia. 